\title{
In Vitro Evaluation of the Antimicrobial Activity of Five Root Canal Sealers
}

\author{
Brenda Paula Figueiredo de Almeida GOMES \\ José Assis PEDROSO \\ Rogério Castilho JACINTO \\ Morgana Eli VIANNA \\ Caio Cezar Randi FERRAZ \\ Alexandre Augusto ZAIA \\ Francisco José de SOUZA-FILHO \\ Department of Restorative Dentistry, Area of Endodontics, Dental School of Piracicaba, UNICAMP, \\ Piracicaba, SP, Brazil
}

\begin{abstract}
The aim of the present study was to analyze the antimicrobial properties of five endodontic sealers: Endo Fill, Endomethasone, Endomethasone N, Sealer 26 and AH-Plus, against the following microorganisms: Candida albicans, Staphylococcus aureus, Enterococcus faecalis, Streptococcus sanguis and Actinomyces naeslundii. The sealers were tested immediately, $24 \mathrm{~h}, 48 \mathrm{~h}$ and $7 \mathrm{days}$ after manipulation. The direct contact method through the observation of the microbial growth in liquid medium and the agar diffusion test were used to evaluate the antimicrobial properties of the sealers. The results, in both methodologies used, showed that immediately after manipulation, Endo-Fill and Endomethasone demonstrated the highest antimicrobial activity, with no statistically significant difference between them. Sealer 26 demonstrated the lowest antimicrobial activity. At all other times after manipulation, there were no statistically significant differences among all the sealers tested. In conclusion, none of the sealers totally inhibited the growth of the microorganisms. Furthermore, the antimicrobial activity of each sealer decreased with time and was dependent upon the microbial susceptibility to them.
\end{abstract}

Key Words: antimicrobial activity, root canal sealers, bacteria, endodontics.

\section{INTRODUCTION}

Root canal therapy is mainly used to prevent and treat periradicular inflammation by the elimination of microorganisms from the root canal system. The most commonly used methods for microbial control include instrumentation, antimicrobial irrigation, intracanal dressing, adequate filling and coronal restoration (1). Antimicrobial activity plays an important role in the efficacy of an endodontic sealer during root canal filling, and for this reason many studies have dealt with the antibacterial activity of endodontic sealers (1-5).

AH-Plus, which is an epoxy resin root canal sealer, has the same physical and chemical properties as AH26 (6) and has been investigated in terms of its antimicrobial properties $(4,5)$. Sealer 26 is another recently developed epoxy resin root canal sealer but it incorporates calcium hydroxide. Its marginal leakage has been studied and its antimicrobial activity seems to be lower than that of Endomethasone (7). Endo-Fill, a zinc oxide-eugenol-based sealer, has shown good impermeability, volume stability, adherence and dissolution $(8,9)$, although it is irritating to periapical tissues (10). It has also shown good antibacterial activity when compared with calcium hydroxide-based sealers (3).

Antimicrobial activity of root canal sealers that contain substances, such as paraformaldehyde, eugenol, and thymol, help destroy the remaining bacteria (2). On the other hand, severe toxicity of a filling material may be a reason for damage of periapical tissues, thereby abolishing the beneficial effects of the antimicrobial properties of the material (11).

Endomethasone is a zinc oxide-eugenol-based (paraformaldehyde-containing) sealer that has shown high antibacterial activity $(2,7)$. However, its paraformaldehyde content has been the subject of discussion due 
to the long-lasting inconvenience and disabling complications caused by the use of drugs that contain such a substance (12). Septodont (Spécialités Septodont, SaintMaur-des-Fossés, Cedex, France) has recently developed Endomethasone N, which does not contain paraformaldehyde in its composition. The cytotoxicity of Endomethasone $\mathrm{N}$ is approximately 30 -fold lower than a formaldehyde-containing sealer. This sealer is also less cytotoxic than AH26, Tubli-Seal and CRCS (11). However, research is necessary to test the properties and antibacterial activities of this new sealer.

Facultative microorganisms such as Enterococcus faecalis and Staphylococcus aureus and even Candida albicans have been considered to be the most resistant species in the oral cavity and possible cause of failure of root canal treatment (13). Thus, the objective of this study was to analyze in vitro the antimicrobial properties of 5 root canal sealers against different microorganisms at different times after manipulation.

\section{MATERIAL AND METHODS}

The sealers used in this study were: Endo-Fill (Herpo Produtos Dentários Ltda., Petrópolis, RJ, Brazil), Endomethasone (Specialités-Septodont, Saint Maur-des-Fossés, Cedex, France); Endomethasone N (Specialités-Septodont), Sealer 26 (Dentsply, Indústria e Comércio Ltda., Petrópolis, RJ, Brazil), and AH-Plus (Dentsply - DeTrey GmbH D-78467, Konstanz, Switzerland). All sealers were mixed according to manufacturer instructions.

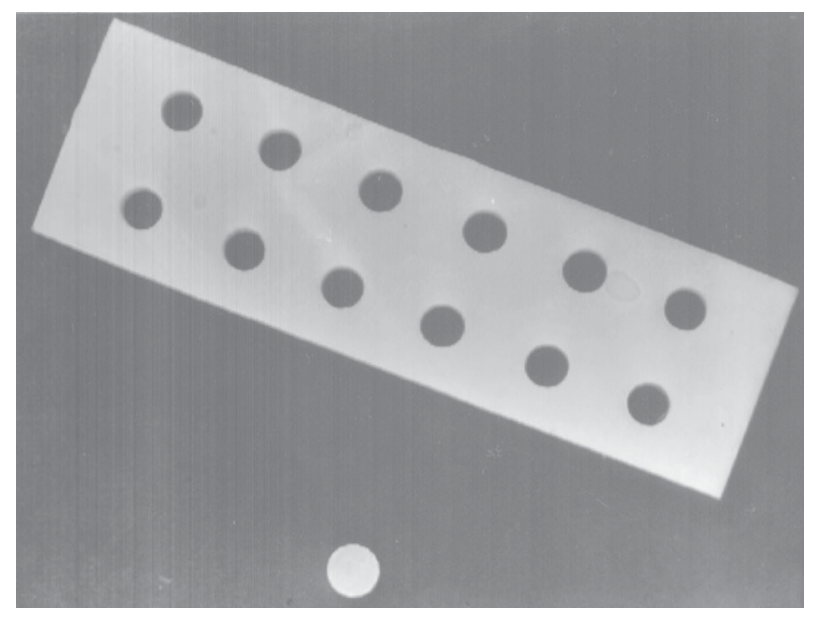

Figure 1. Teflon apparatus used to standardize the size of the holes in which the sealer was introduced and left to set, providing similar sealer tablets.

\section{Antimicrobial Activity}

In order to have the same sealer volume, $0.2 \mathrm{~mL}$ of freshly prepared sealer was introduced into standard holes $(5 \times 4 \mathrm{~mm})$ of a sterile Teflon apparatus (Figure 1). The sealers were tested immediately, $24 \mathrm{~h}, 48 \mathrm{~h}$ and 7 days after manipulation and were kept inside the Teflon apparatus, which was placed in an incubator at $37^{\circ} \mathrm{C}$ until the beginning of the experiment (except the ones used immediately after manipulation).

The following bacteria were used to evaluate the antimicrobial activity of the sealers: Enterococcus faecalis (ATCC 29212), Staphylococcus aureus (ATCC 25923), Streptococcus sanguis (ATCC 10556), Actinomyces naeslundii (M 104) and Candida albicans (NTCC 3736).

Two standard methods were used to investigate the antimicrobial activity of the sealers: direct contact and agar diffusion.

\section{Direct Contact Method}

The pure cultures were grown on 5\% sheep blood plus brain heart infusion (BHI) agar plates (Oxoid, Basingstoke, UK). After $24 \mathrm{~h}$, the colonies were suspended in tubes containing $5 \mathrm{~mL}$ of brain heart infusion (BHI) broth (Oxoid). The cell suspension in each tube was adjusted spectrophotometrically at $800 \mathrm{~nm}$ (O.D. ${ }_{800}$ ) to match the transmittance of $90 \mathrm{~T}$ (equivalent to $0.5 \mathrm{McFarland}$ scale $=1.5 \times 10^{8} \mathrm{cfu}$ ).

The following systems were tested: antimicrobial activity was checked hourly, using the spectrophotometer, up to the $18^{\text {th }} \mathrm{h}$ for $\mathrm{BHI}+$ inoculum + sealer; microbial growth was checked hourly up to the $18^{\text {th }} \mathrm{h}$ for BHI + inoculum; sealer dissolution was checked hourly up to the $18^{\text {th }} \mathrm{h}$ for BHI + sealer. Tubes containing only microorganisms were used as positive controls. Aliquots $(10 \mu \mathrm{L})$ of each system were collected hourly up to the $18^{\text {th }} \mathrm{h}$ and inoculated into $5 \%$ blood $+\mathrm{BHI}$ agar plates, which were incubated for $18-24 \mathrm{~h}$ under adequate gaseous conditions, in order to check microbial growth. The purity of the positive cultures was confirmed by Gram staining, by colony morphology on blood agar plates and by the use of biochemical identification kits [Rapid ID 32 A, Bio Mérieux, Marcyl'Etoile, France, for Gram-positive rods; API Staph, Bio Mérieux, for staphylococci (Gram-positive cocci, catalase-positive); API 20 Strep, Bio Mérieux, for strep- 
tococci (Gram-positive cocci, catalase-negative) and ID 32C, BioMérieux, for yeast identification].

\section{Agar Diffusion Method}

The methodology used was adapted from Gomes et al. (13). All microorganisms were previously subcultured in appropriate culture media and under gaseous conditions to confirm their purity.

Aerobe and facultative strains were individually inoculated into tubes containing $5 \mathrm{~mL}$ of a sterile $0.85 \%$ saline solution. The suspension was adjusted spectrophotometrically at $800 \mathrm{~nm}$ (O.D. $\left.{ }_{800}\right)$ to match the transmittance of $90 \mathrm{~T}$ (equivalent to $0.5 \mathrm{McF}$ arland scale $=1.5 \times 10^{8} \mathrm{cfu}$ ). Five hundred $\mu \mathrm{L}$ of each test microorganism suspension was inoculated into glass bottles containing $50 \mathrm{~mL}$ of $\mathrm{BHI}$ Agar at $46^{\circ} \mathrm{C}$, vortexed, and poured onto $130-\mathrm{mm}$ plates containing a previously set layer of Mueller Hinton (MH) agar (Oxoid).

Sterile stainless-steel tubes $(8.0$ × 1.0 x $10 \mathrm{~mm}$;

Table 1. Antimicrobial activity of sealers (immediately, $24 \mathrm{~h}, 48 \mathrm{~h}$, and 7 days after manipulation) against microorganisms (mean value from 0 to $18 \mathrm{~h}$ ).

\begin{tabular}{lccccc}
\hline & Endo Fill & Endometh & Endometh N & Sealer 26 & AH Plus \\
\hline C. albicans & & & & & \\
Immediately & 70.02 & 68.44 & 62.83 & 25.46 & 54.43 \\
24 h & 49.33 & 72.74 & 64.07 & 48.89 & 54.94 \\
48 h & 44.98 & 46.74 & 59.38 & 46.51 & 48.28 \\
7 days & 43.16 & 47.65 & 50.43 & 41.94 & 45.60 \\
A. naeslundii & & & & & \\
Immediately & 75.74 & 76.91 & 73.10 & 15.70 & 34.86 \\
24 h & 40.60 & 36.20 & 71.20 & 37.36 & 37.70 \\
48 h & 41.68 & 35.83 & 60.40 & 41.40 & 46.60 \\
7 days & 40.49 & 38.56 & 33.53 & 41.64 & 45.83 \\
E. faecalis & & & & & \\
Immediately & 34.49 & 78.80 & 27.54 & 21.15 & 35.43 \\
24 h & 40.99 & 33.82 & 23.43 & 33.21 & 36.13 \\
48 h & 35.24 & 38.01 & 21.90 & 34.92 & 34.78 \\
7 days & 36.45 & 32.13 & 21.60 & 41.94 & 37.39 \\
S. aureus & & & & & \\
Immediately & 85.00 & 88.60 & 84.72 & 16.80 & 85.72 \\
24 h & 76.73 & 43.56 & 55.17 & 62.97 & 64.16 \\
48 h & 53.82 & 41.85 & 36.49 & 42.70 & 47.64 \\
7 days & 50.91 & 43.16 & 39.46 & 41.02 & 45.98 \\
S. sanguis & & & & & \\
Immediately & 73.15 & 72.10 & 82.00 & 6.83 & 50.56 \\
24 h & 74.04 & 67.40 & 72.22 & 49.12 & 47.06 \\
48 h & 72.18 & 62.74 & 59.55 & 49.74 & 49.50 \\
7 days & 70.73 & 47.34 & 53.39 & 53.36 & 43.52 \\
\hline & & & & &
\end{tabular}

inner diameter, $6 \mathrm{~mm}$ ) were added to the surfaces of the media and filled with $40 \mu \mathrm{L}$ of each sealer freshly manipulated and its control. Sealers manipulated after $24 \mathrm{~h}, 48 \mathrm{~h}$ and 7 days were kept inside the Teflon apparatus, which was placed in an incubator at $37^{\circ} \mathrm{C}$ until the beginning of the experiment. The sealers in tablets were transferred from the Teflon apparatus to the media surface. The plates were kept for $2 \mathrm{~h}$ at room temperature to allow the diffusion of the agents through the agar and then incubated at $37^{\circ} \mathrm{C}$ under appropriate gaseous conditions and for an appropriate period of time: aerobes, $24 \mathrm{~h}$; facultative, 24-48 h in a $\mathrm{CO}_{2}$ incubator (Jouan, Saint Herblain, France), in an atmosphere of $10 \% \mathrm{CO}_{2}$.

Zones of inhibition of microbial growth around the cylinder containing the tested substances, and around the sealer tablets were measured and recorded after the incubation period. The inhibitory zone was considered to be the shortest distance $(\mathrm{mm})$ from the outer margin of the cylinder or sealer tablet to the initial point of microbial growth. Six replicates were made for each microorganism. Analysis of variance (ANOVA) was used to determine the differences in susceptibility to endodontic sealers between microbial species.

\section{RESULTS}

\section{Direct Contact Method}

Table 1 shows the antimicrobial activity of each sealer tested (immediately, $24 \mathrm{~h}, 48 \mathrm{~h}$, and 7 days after manipulation) against each microorganism tested, (mean value from 0 to 18 hours), using the direct contact test.

Immediately after manipulation, Endo-Fill, Endomethasone and Endomethasone $\mathrm{N}$ presented the highest antimicrobial activity, with no statistically significant difference between them. Sealer 26 had the lowest antimicrobial activity. Nevertheless, at the other manipulation times there were no statistically significant differences among the sealers tested.

Table 2 shows the mean values of 
the antimicrobial activity of all sealers against all microorganisms used. Endomethasone $\mathrm{N}$ presented the highest antimicrobial activity against $A$. naeslundii, and Endo-Fill against $S$. aureus. Endo-Fill and Endomethasone $\mathrm{N}$ presented the best performance against $S$. sanguis. Endomethasone N was also the most effective sealer against $C$. albicans, although its results were almost the same as those obtained with Endomethasone. E. faecalis was the microorganism showing the greatest resistance against all sealers tested, being more affected by Endomethasone. The most susceptible microorganisms to all sealers tested were $S$. sanguis and $S$. aureus.

There were no statistically significant differences among sealers in terms of dissolution when in

Table 2. Mean values of the antimicrobial activity of 5 sealers against microorganisms tested.

\begin{tabular}{|c|c|c|c|c|c|c|}
\hline & Endo Fill & Endometh & Endometh N & Sealer 26 & AH Plus & $\begin{array}{c}\text { Average } \\
\text { microbial } \\
\text { susceptibility } \\
\text { to sealers }\end{array}$ \\
\hline C. albicans & 51.87 & 58.89 & 59.18 & 40.70 & 50.81 & 52.29 \\
\hline A. naeslundii & 49.62 & 46.87 & 59.55 & 34.04 & 41.34 & 46.28 \\
\hline E. faecalis & 36.79 & 45.69 & 23.62 & 32.80 & 35.94 & 34.96 \\
\hline S. aureus & 66.61 & 54.29 & 53.96 & 40.77 & 60.87 & 55.30 \\
\hline S. sanguis & 72.49 & 62.61 & 68.16 & 39.76 & 47.66 & 58.13 \\
\hline \multicolumn{7}{|c|}{ Average antimicrobial activity of sealers for microorganisms } \\
\hline & 55.47 & 53.67 & 52.89 & 37.61 & 47.32 & \\
\hline
\end{tabular}

Table 3. Zones of inhibition of microbial growth of each sealer against all microorganisms tested.

\begin{tabular}{|c|c|c|c|c|c|c|}
\hline & Endo-Fill & Endometh & Endometh N & Sealer 26 & AH Plus & $\begin{array}{l}\text { Average inhibi- } \\
\text { tion zone of } \\
\text { microorganism } \\
\text { for sealers }\end{array}$ \\
\hline C. albicans & 1.92 & 1.00 & 0.85 & 0 & 0.62 & 0.88 \\
\hline A. naeslundii & 2.05 & 0.87 & 0 & 0.07 & 0 & 0.75 \\
\hline E. faecalis & 0 & 0.82 & 0 & 0 & 0 & 0.20 \\
\hline S. aureus & 0.25 & 1.50 & 0 & 0.25 & 0.32 & 0.58 \\
\hline S. sanguis & 1.12 & 0.75 & 0.70 & 0 & 0.45 & 0.58 \\
\hline \multicolumn{7}{|c|}{ Average inhibition zone of sealers for microorganisms } \\
\hline & 1.07 & 0.99 & 0.31 & 0.06 & 0.28 & \\
\hline
\end{tabular}

$0=$ Direct contact inhibition only contact with the liquid medium.

The transmittance values of each sealer in liquid medium ("sealer dissolution") were smaller than the values of each microorganism growing in liquid medium ("microbial growth"), at $18 \mathrm{~h}$. Therefore, there were no statistically significant differences between sealer dissolution and microbial growth.

Microbial growth and sealer dissolution were checked hourly up to the $18^{\text {th }} \mathrm{h}$ by inoculating $10 \mu \mathrm{L}$ of the suspension medium in agar plates to certify that the transmittance values achieved were due to the microbial growth and not to the sealer dissolution. No sealer totally inhibited the microorganisms tested, as observed by the microbial growth on the agar plates.

\section{Agar Diffusion Method}

Table 3 shows the zones of inhibition of microbial growth and the average values of the antimicrobial activity of each sealer against all microorganisms tested. Endo-Fill produced the largest inhibitory zone, followed by Endometh-asone and and Endomethasone N. On the other hand, Sealer 26 produced the smallest inhibitory zone. All sealers had antimicrobial activity by direct contact at least. In general, C. albicans was the most susceptible microorganism using the agar diffusion test, whereas E.faecalis was the most resistant.

\section{DISCUSSION}

The direct contact test used in this study was based on the reading of the transmittance values in the spectrophotometer, which provides turbidimetrically the determination of microbial growth. The higher the transmittance value the higher was the antimicrobial activity (i.e. less microbial growth). The 
methodology used was adapted from Weiss et al. (14) and Shalhav et al. (15). However, these authors did not test the same sealers, so it was impossible to compare our results with theirs.

The direct contact test relies on direct and close contact between the test microorganism and the tested material, and is independent of the diffusion properties of the tested material and the media, which is an advantage over other tests like the agar diffusion method (14).

Microbial growth and sealer dissolution were checked hourly up to the $18^{\text {th }} \mathrm{h}$ because pilot studies showed that this was the optimum growth phase of the tested microorganisms.

Enterococcus faecalis was the most resistant microorganism and Streptococcus sanguis the most susceptible, but none of the sealers tested killed $100 \%$ of the microbial cells. Nevertheless, the zinc oxideeugenol-based sealers had a higher antimicrobial activity than the epoxy resin-based sealers.

In general, the antimicrobial activity of Endomethasone and Endomethasone $\mathrm{N}$ was approximately the same, suggesting that the presence of paraformaldehyde did not increase the antimicrobial action of Endomethasone against the microorganisms tested. The absence of paraformaldehyde in the composition of Endomethasone $\mathrm{N}$ follows a world tendency to remove toxic substances from the composition of biological materials.

The agar diffusion method has been widely used to test the antimicrobial activity of dental materials and medications $(1,3)$. The advantage of this method is that it allows direct comparisons of root canal sealers against the test microorganisms, indicating which sealer has the potential to eliminate bacteria in the local microenvironment of the root canal system.

A disadvantage of the agar diffusion test is that the result of this method does not depend only on the toxicity of the material for the particular microorganism, but is also highly influenced by the diffusibility of the material across the medium. A material that diffuses more easily will probably provide larger zones of microbial growth inhibition $(1,16,17)$. However, great care was taken to keep the plates for $2 \mathrm{~h}$ at room temperature to allow the diffusion of the agents through the agar and then incubated at $37^{\circ} \mathrm{C}$ under appropriate gaseous condition.

According to our results, Endo-Fill and Endomethasone produced the largest inhibitory zones of the microbial growth against all microorganisms studied in all times after manipulation. Sealer 26, AH plus and Endomethasone $\mathrm{N}$ showed the smallest inhibitory zones in the same experimental conditions.

Our findings agree with studies that found large inhibitory zones produced by sealers similar to EndoFill such as Grossman's sealer $(1,17)$ and Procosol $(4)$, against microorganisms such as $S$. aureus $(1,4) C$. albicans $(4,17)$ and E. faecalis (17) which were also used in our study.

Although Endomethasone and Endo-Fill are both zinc oxide-eugenol-based, Canalda and Pumarola (18) noted that the paraformaldehyde sealer Endomethasone showed the largest inhibitory zones. On the other hand, we did not find statistically significant differences between these two sealers. Another zinc oxideeugenol-based sealer containing formaldehyde, N2, proved to be more effective against $S$. aureus and $S$. sanguis than AH plus $(17,19)$. In the present study, Endomethasone was also better than AH Plus.

Sealer 26 and AH Plus were similar to Endomethasone N, and all of them were worse than EndoFill and Endomethasone. In other studies, Sealer 26 and AH Plus have shown inhibitory zones smaller than zinc oxide-eugenol-based sealers (4).

In both methodologies, all sealers tested demonstrated a higher antimicrobial value in the first $24 \mathrm{~h}$ after manipulation, which seems interesting, especially knowing that microorganisms can remain in the ramifications of the root canal system after chemomechanical preparation and intracanal dressing. Having antimicrobial activity, the sealers can act against such microorganisms, reducing their numbers and providing a better chance of successful root canal treatment.

The fact that the in vitro antimicrobial activity reduces with time is also important, because it could mean that the sealers become more stable in contact with the body fluids.

The present study tested the antimicrobial activity of 5 sealers against microorganisms considered to be resistant to endodontic treatment. Therefore, it means that if a sealer is effective against these microorganisms, it will probably be effective against the more susceptible ones.

None of the sealers tested totally inhibited the microbial growth, and the antimicrobial activity of each sealer decreased with time and depended on the microbial susceptibility to them. Thus, endodontic treatment 
must be carried out under aseptic conditions, using a powerful irrigant solution, an intracanal medicament when necessary, a sealer with antimicrobial activity and an effective coronal seal to prevent coronal microleakage in order to increase the chances of successful root canal treatment.

\section{RESUMO}

O objetivo do presente estudo foi analisar as propriedades antimicrobianas de cinco cimentos endodônticos: Endo Fill, Endomethasone, Endomethasone N, Sealer 26 e AH-Plus, em diferentes períodos pós-manipulação, i.e., imediatamente e após 24 horas, 48 horas e 7 dias, contra os seguintes microrganismos: Candida albicans, Staphylococcus aureus, Enterococcusfaecalis, Streptococcus sanguis e Actinomyces naeslundii. Os métodos usados foram o contato direto através da observação do crescimento microbiano em meio líquido e o teste de difusão em agar. Os resultados, nas duas metodologias usadas, mostraram que: 1) imediatamente após a manipulação, Endo-Fill e Endomethasone apresentaram a maior atividade antimicrobiana, sem diferenças estatisticamente significantes entre eles. Sealer 26 teve a menor atividade antimicrobiana; 2) nos outros tempos pós-manipulação, não houveram diferenças estatisticamente significantes entre os cimentos testados. Foi concluído que nenhum dos cimentos inibiu completamente o crescimento dos microrganismos testados. A atividade antimicrobiana de cada cimento diminuiu com o tempo e dependeu da suscetibilidade microbiana a eles.

\section{ACKNOWLEDGEMENTS}

We would like to thank Dr. M. Campbell from the University of Manchester, UK, for invaluable statistical help and Mr. Adailton dos Santos Lima for technical support. This work was supported by the Brazilian agencies FAPESP (2000/13689-7), CNPq (520277/996, 304282/2003-0) and CAPES.

\section{REFERENCES}

1. al-Khatib ZZ, Baum RH, Morse DR, Yesilsoy C, Bhambhani S, Furst ML. The antimicrobial effect of various endodontic sealers. Oral Surg 1990;70:784-790.
2. Pumarola J, Berastegui E, Brau E, Canalda C, Jimenez de Anta MT. Antimicrobial activity of seven root canal sealers. Oral Surg 1992;74:216-220.

3. Siqueira Jr JF, Gonçalves RB. Antibacterial activities of root canal sealers against selected anaerobic bacteria. J Endod 1996;22:79-80.

4. Kaplan AE, Picca M, Gonzalez MI, Macchi RL, Molgatini SL. Antimicrobial effect of six endodontic sealers: an in vitro evaluation. Endod Dental Traumatol 1999;15:42-45.

5. Leonardo MR, da Silva LA, Tanomaru Filho M, Bonifácio KC, Ito IY. In vitro evaluation of antimicrobial activity of sealers and pastes used in endodontics. J Endod 2000;26:391-394.

6. Al-Khatar N, Kunzelmann KH, Hickel R. Apical leakage of new root canal sealers. J Dental Res 1995;74:945 [Abstr 273].

7. Orstavik D. Antibacterial properties of root-canal sealers, cements and pastes. Int Endod J 1981;14:125-133.

8. Holland R, de Souza V, Abdalla T, Russo MC. Sealing properties of some root-canal filling materials evaluated with radioisotope. Austr Dental J 1974;19:322-325.

9. Benatti O, Stolf WL, Ruhnke LA. Verification of the consistency, sitting time and dimensional changes of root canal filling materials. Oral Surg 1978;46:107-113.

10. Barbosa SV, Araki K, Spangberg LSW. Cytotoxicity of some modified root canal sealers and their leakable components. Oral Surg 1993;75:357-361.

11. Ersev H, Schmalz G, Bayirli G, Schweikl H. Cytotoxic and mutagenic potencies of various root canal filling materials in eukaryotic and prokaryotic cells in vitro. J Endod 1999;5:359363.

12. Kaufman AY, Rosenberg L. Paresthesia caused by Endomethasone. J Endod 1980;6:529-531.

13. Gomes BPFA, Ferraz CCR, Vianna ME, Rosalen PL, Zaia AA, Teixeira FB, Souza-Filho FJ. In vitro antimicrobial activity of calcium hydroxide pastes and their vehicles against selected microorganisms. Braz Dent J 2002;13:155-161.

14. Weiss EI, Shalhav M, Fuss Z. Assessment of antibacterial activity of endodontic sealers by a direct contact test. Endod Dental Traumatol 1996;12:179-184.

15. Shalhav M, Fuss Z, Weiss E. In vitro antibacterial activity of a glass ionomer endodontic sealer. J Endod 1997;23:616-619.

16. Abdulkader A, Deguid R, Saunders EM. The antimicrobial activity of endodontic sealers to anaerobic bacteria. Int Endod J 1996;29:280-283.

17. Siqueira Jr JF, Favieri A, Gahyva SMM, Moraes SR, Lima KC, Lopes HP. Antimicrobial activity and flow rate of newer and established root canal sealers. J Endod 2000;5:274-277.

18. Canalda C, Pumarola J. Bacterial growth inhibition produced by root canal sealer cements with a calcium hydroxide base. Oral Surg 1989;1:99-102.

19. Lai CC, Huang FM, Yang HW, Chan Y, Huang MS, Chou MY, Chang YC. Antimicrobial activity of four root canal sealers against endodontic pathogens. Clin Oral Invest 2001;5:236-239. 